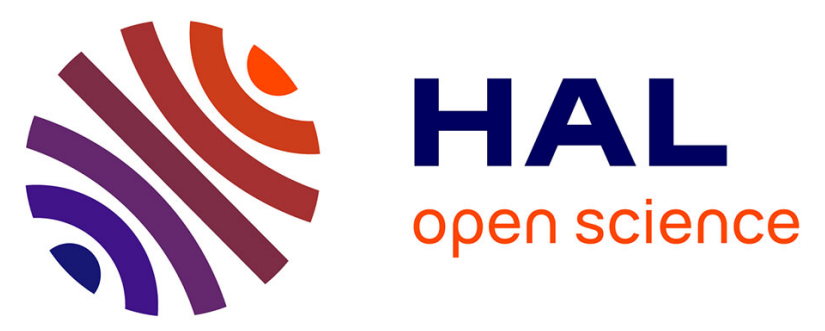

\title{
Time-resolved X-ray diffraction studies of structural transitions in organic polymers using synchrotron radiation
}

W. Fuller, A. Mahendrasingam, A. Jaber, C. Martin, D. Hughes, R. Oldman, D. Blundell, D. Mackerron

\section{To cite this version:}

W. Fuller, A. Mahendrasingam, A. Jaber, C. Martin, D. Hughes, et al.. Time-resolved X-ray diffraction studies of structural transitions in organic polymers using synchrotron radiation. Journal de Physique IV Proceedings, 1994, 04 (C9), pp.C9-195-C9-198. 10.1051/jp4:1994934 • jpa-00253495

\section{HAL Id: jpa-00253495 https://hal.science/jpa-00253495}

Submitted on 1 Jan 1994

HAL is a multi-disciplinary open access archive for the deposit and dissemination of scientific research documents, whether they are published or not. The documents may come from teaching and research institutions in France or abroad, or from public or private research centers.
L'archive ouverte pluridisciplinaire HAL, est destinée au dépôt et à la diffusion de documents scientifiques de niveau recherche, publiés ou non, émanant des établissements d'enseignement et de recherche français ou étrangers, des laboratoires publics ou privés. 


\title{
Time-resolved X-ray diffraction studies of structural transitions in organic polymers using synchrotron radiation
}

\author{
W. Fuller, A. Mahendrasingam, A. Jaber, C. Martin, D. Hughes, R.J. Oldman*, D.J. Blundell** \\ and D. MacKerron** \\ Department of Physics, Keele University, Keele, Staffordshire, ST5 5BG, U.K. \\ * ICI Chemicals and Polymers, Runcorn, Cheshire, WA7 4QD, U.K. \\ ** ICI Wilton Research Centre, Middlesbrough, Cleveland TS6 8JE, U.K.
}

\begin{abstract}
The high brilliance of the Daresbury Synchrotron Radiation Source has been exploited in time-resolved $\mathbf{x}$-ray fibre diffraction of changes in polymer conformation and organisation in response to patterns of mechanical and thermal stress similar to those followed during industrial processing. This has involved the development of a new $\mathrm{x}$-ray camera which can be used in both wide and small angle diffraction and allows uniaxial drawing for draw rates up to $72,000 \%$ per minute (i.e. an increase in length by a factor of 720 in one minute) at temperatures from ambient to $400^{\circ} \mathrm{C}$. The use of electronic area detectors which display the diffraction pattern while it is recorded allow experiments to be conducted in real-time. The variation in the diffraction is recorded as a series of frames. The time to record a frame can be as short as $\mathbf{4 0}$ msecs.
\end{abstract}

\section{INTRODUCTION}

X-ray fibre diffraction studies, particularly since the second World War, have been central to the provision of structural information on both the conformation of polymer molecules and the arrangement of polymer chains. The increasing availability of synchrotron sources has had a major impact on the information obtainable by these methods. Not only has this resulted in more detailed static pictures of polymer molecules, but increasingly it is providing time-dependent information which allows stereochemical pathways followed in response to thermal and mechanical stress to be characterised(1). Such time resolved studies are well illustrated by parallel wide angle $x$-ray scattering (WAXS) and small angle $x$-ray scattering (SAXS) of the drawing and annealing of the high performance industrial polymer poly arylether-ether-ketone (PEEK). The time resolution achieved was sufficient for the observation of a transitory loss of orientation in the WAXS pattern which persisted for less than one minute while a cold drawn sample was annealed around the glass transition. No indication of this transition had been obtained using conventional laboratory based rotating anode sources. This observation and the subsequent development of a highly crystalline and oriented WAXS pattern has been interpreted in terms of two processes. The first is a loss of polymer chain orientation analogous to the entropy driven change during relaxation in natural rubbers. The second is a much slower transition associated with the untangling of polymer chains(2). This interpretation in terms which are not specific to the detailed stereochemistry of PEEK has prompted parallel investigations of other organic polymers. This report compares observations on polyethylene terephthalate (PET) and poly phenyl sulphide (PPS) under conditions analogous to those used in the study of PEEK. 


\section{MATERIALS AND METHODS}

All the polymer materials studied were initially in the form of unoriented, non-crystalline sheets a few hundred microns thick. The x-ray camera used to record both WAXS and SAXS patterns was developed from an earlier model, purpose-designed and constructed in this laboratory(3). In the more recent design the upper limit in the temperature range over which the specimen can be studied has been increased to $400^{\circ} \mathrm{C}$ and the rate at which bidirectional uniaxial drawing can be performed can be varied from $4 \%$ per minute to $72,000 \%$ per minute, i.e. to an upper limit comparable to draw rates used in industrial processing. The improved camera also incorporates a strain gauge and is interfaced to a computer based data acquisition system which allows continuous monitoring of temperature, mechanical parameters and gross appearance of the specimen. Diffraction data can be recorded using photographic film or an electronic area detector. We have generally preferred electronic area detectors because of their advantages of shorter exposure time and hence improved time resolution and their ability to allow genuinely real time experiments. An Enraf Nonius FAST TV detector was installed on the WAXS beamline 9.6 at the Daresbury SRS, a multi-wire proportional counter was installed on the SAXS beamline 2.1. A Photonic Science detector linked to a Synoptics i860 frame-grabber could, because of its high degree of portability and flexibility, be used on both WAXS and SAXS beamlines. Examples of diffraction data recorded using these detectors are illustrated in Figures 1 to 4 .

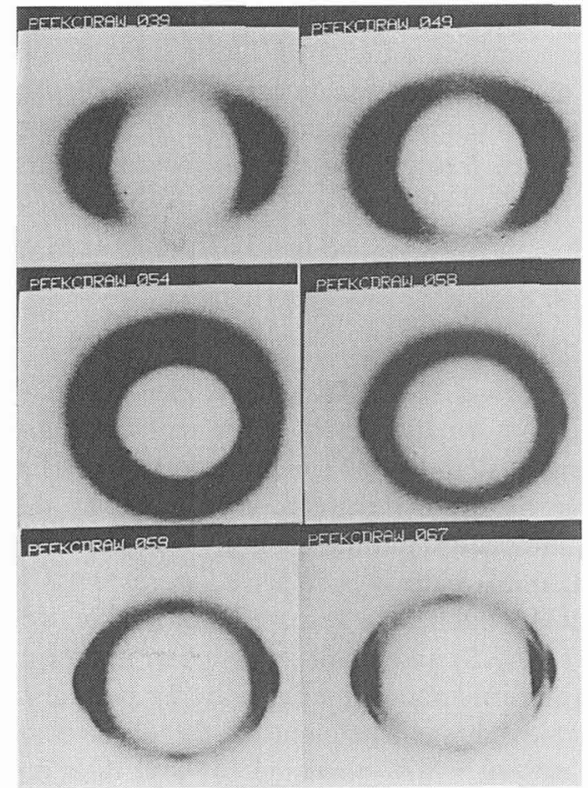

Figure 1: WAXS study of annealing of cold drawn PEEK. The original orientation in the diffraction at $5 \AA$ was briefly lost (frame 054) but recovered during subsequent crystallisation. Data recorded with $10 \mathrm{~s}$ exposure using FAST detector.

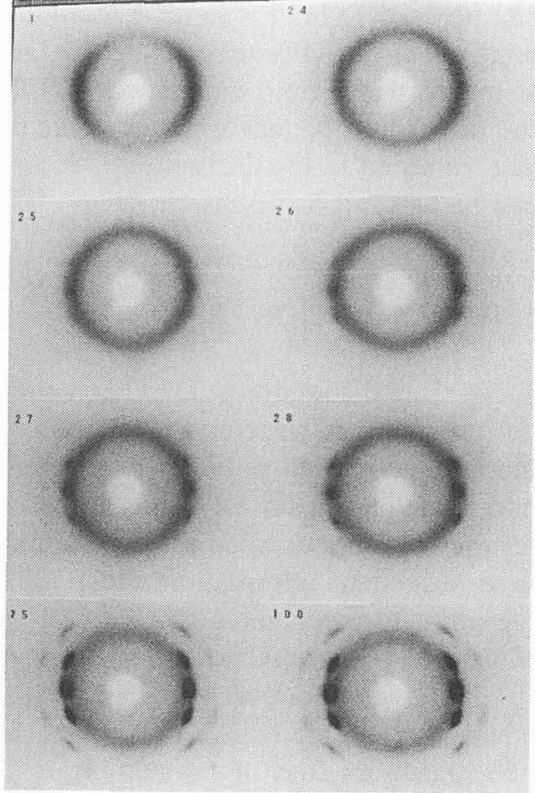

Figure 2: Parallel study of PPS to that for PEEK showing the transitory loss in the the original orientation of the diffraction at $5 \AA$ and subsequent development of crystallinity. Data recorded with $5 \mathrm{~s}$ exposure using Photonic Science detector. 


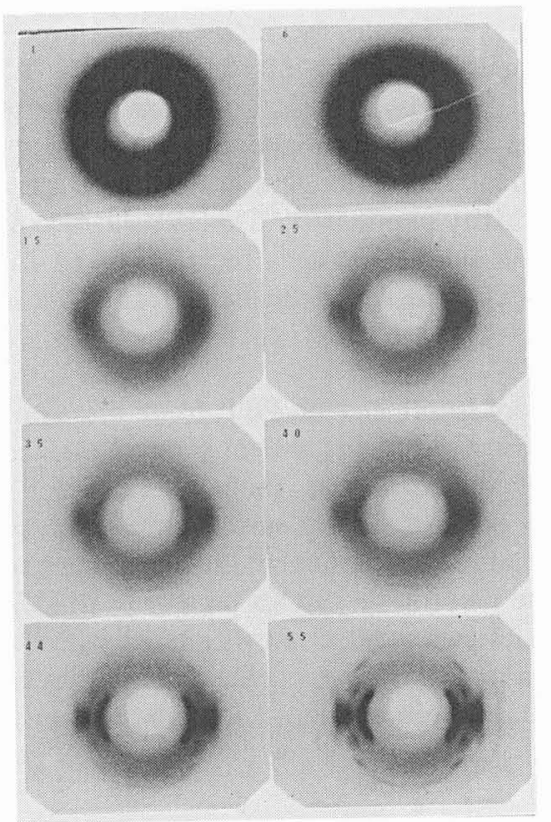

Figure 3: WAXS study of PET during drawing at $80^{\circ} \mathrm{C}$ and subsequent annealing to $160^{\circ} \mathrm{C}$ showing development of orientation and crystallinity within the original $5 \AA$ diffraction ring. Data recorded with $5 \mathrm{~s}$ exposure using FAST detector.

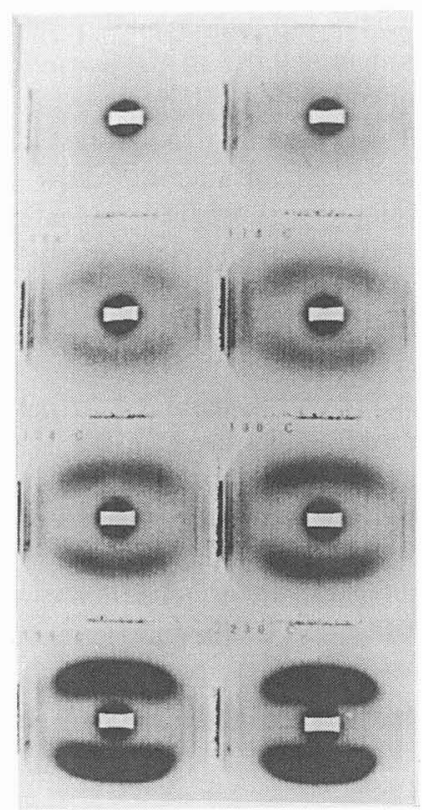

Figure 4: SAXS study of PET which paralleled the WAXS study in Figure 3 showing development of meridional diffraction at $140 \AA$. Data recorded with 30 s exposure using a MWPC.

\section{EXPERIMENTAL OBSERVATIONS}

WAXS diffraction patterns which illustrate the temporary loss of orientation observed during annealing of cold drawn specimens of PEEK around the glass transition are illustrated in Figure 1. Figure 2 illustrates changes in the WAXS patterns observed during a parallel experiment on PPS. From these figures it can be seen that there is a comparable transitory loss of orientation for PPS to that reported for PEEK, once allowance is made for the lower glass transition of PPS i.e. $96^{\circ} \mathrm{C}$ compared with $143^{\circ} \mathrm{C}$.

The WAXS and SAXS studies of the drawing and annealing of PET are very extensive and will be discussed in detail elsewhere. However, in the context of comparing the behaviour of this polymer to PEEK and PPS, WAXS and SAXS observations on slowly drawn (i.e. $20 \% / \mathrm{min}$ ) samples of PET within the temperature range $80^{\circ} \mathrm{C}$ to $100^{\circ} \mathrm{C}$ are of particular interest (Figures 3 and 4).

\section{CONCLUSIONS}

i. The transitory loss of orientation during annealing of a cold drawn specimen of PEEK around the glass transition (Figure 1) is also observed for PPS, although the degree of disorder is not so pronounced (Figure 2). 
ii. Specimens of non-crystalline unoriented samples of PET slowly drawn at temperatures less than $\sim 95^{\circ} \mathrm{C}$ to a draw ratio (i.e. final length divided by initial length) of $\sim 3.5$ orient and give highly crystalline diffraction patterns on subsequent annealing to $160^{\circ} \mathrm{C}$ (Figure 3). In contrast identical samples slowly drawn at temperatures greater than $\sim 95^{\circ} \mathrm{C}$ to a similar draw ratio do not orient and although a crystalline pattern develops on subsequent annealing this is essentially unoriented. This dependence of the orientation on draw temperature has some similarities to effects observed for PEEK and we are currently investigating the extent to which the behaviour of these two polymers may have a common origin.

iii. SAXS patterns recorded in parallel studies on specimens of PET from the same material as that used for the WAXS studies discussed in (ii) above, showed marked changes in the diffraction at $\sim 140 \AA$ as the specimen was annealed (Figure 4). However, the features observed in the SAXS patterns during such a time-resolved experiment also depend on the draw temperature. In particular there are marked differences in the inclination of the arms of the cross in the SAXS pattern from PET as a function of the draw temperature. Material drawn at $80^{\circ} \mathrm{C}$ shows a cross with the arms oriented at approximately $45^{\circ}$ to the horizontal. However, for material drawn at $90^{\circ} \mathrm{C}$ the arms are inclined at a larger angle to the horizontal and material drawn at $100^{\circ} \mathrm{C}$ gives an unoriented pattern. All these samples were drawn at $20 \%$ per minute.

iv. The development of the lamellae identified with crystalline regions within the fibre as indicated by diffraction around $140 \AA$ in the SAXS pattern from PET (Figure 4) occurs at the same stage in annealing as the development of crystallinity as indicated by the WAXS pattern (Figure 3). A similar correlation between changes in SAXS and WAXS patterns occurs for PEEK.

The relationship between draw temperature, draw rate, annealing rate and draw ratio for polymer materials like those studied here is clearly complex reflecting fundamental features of polymer structure and organisation. We are attempting to clarify these interactions to develop a more complete understanding of the factors important in influencing crystallinity and orientation and hence a wide variety of mechanical properties in industrial organic polymers.

\section{ACKNOWLEDGEMENTS}

We are grateful to the SERC for support through grant GR/H/67966 to (AMS, WF, RJO and DJB) and for allocations of beam time at the Daresbury SRS.

\section{REFERENCES}

(1) Fuller, W., Forsyth, V.T. and Mahendrasingam, A., Synchrotron Radiation in Biophysics, edited by S. Hasnain (Ellis Horwood, Chichester, UK, 1990), pp. 201-222.

(2) Blundell, D.J., Mahendrasingam, A., MacKerron, D., Turner A., Rule, R., Oldman, R.J. and Fuller, W., Polymer (in Press, 1994)

(3) Mahendrasingam, A., Fuller, W., Forsyth, V.T., Oldman, R.J., MacKerron, D. and Blundell, D.J., Rev. Sci. Instrum., (1992) 63(1), pp. 1087-1090. 